\title{
Japan's graduate university matures
}

The long-standing concern in Japan about the shortage of indigenous PhDs will be partly met by the graduate university about to graduate its first cohort of students.

\section{Hakone}

IT was shown last week that all the students and most of the faculty of Japan's unique graduate school without a campus yet to call its own can still be crammed into a modest meeting hall at this mountain lakeside summer resort between Tokyo and Mount Fuji. But not for much longer. The education council of the Ministry of Education, Science and Culture (MESC) is likely on Friday this week (13 September) to have approved a plan to double student numbers to more than 250 . Next spring, when the university will be graduating its first PhDs, there may also be agreement on a permanent campus at Hayama to replace the present mailing address at Yokohama.

The origins of the Graduate University for Advanced Studies lie in the heartsearching in Japan during the 1980 s over the conundrum often over-simplified as: "Why is Japan outstanding at technology, but less so at basic science?" The same issue also stimulated the debate in the 1980s about 'creativity' (or the supposed lack of it). The explanation was accurately found where it might have been sought in the first place, in the pattern of research and education at Japanese university departments and in the predilections of Japanese employers.

Briefly, the great Japanese companies (whose business decisions ensure that 75 per cent of Japan's research and development is privately financed) prefer new recruits who are not free-standing scientists and engineers, but people still amenable to training. Some academics put this differently, saying that the companies prefer to recruit people who are still malleable. Whatever the best form of words, the effect is that there are many masters' degrees, but many fewer homegrown PhDs - fewer even than in Britain (see page 105). Because the best-equipped university departments are often those enjoying industrial research and development contracts, a master's course may often be seamlessly connected with the induction to a lifelong career in industry that usually follows.

The Graduate University is MESC's first response, but it is generally agreed that the university would not so quickly have come into being without the persistence and guile of Saburo Nagakura, its first president, who was the director of the Institute of Molecular Science at Okazaki until 1986. Nagakura, unlike most Japa- nese, lets his ambitions show - he says that he wants his university to grow until there are "at least 1,000 students", for example. It is easy to imagine him not taking "No" for an answer. One colleague said this week that while he may not be universally popular, "he's necessary for Japan".

The idea of the university is simple, the practice a little more complicated. Over the years, Japan has acquired a group of basic research institutes (of which that best-known internationally is the National Institute for High-Energy Physics, or 'KEK', at Tsukuba) which exist to provide cooperative research facilities for the national universities, but whose permanent members of staff are inevitably isolated from teaching. So why not link them with a body of students recruited from the universities, but including a sprinkling from overseas? The notion has been in the air since 1982, but became a reality only in October 1988.

There are now seven parent institutes. As well as Nagakura's old institute at Okazaki, the two other national institutes on that site (for basic biology and physiological studies) have joined up. So too have the National Institute of Genetics at Mishima, the Institute for Statistical Mathematics at Tokyo, the National Museum for Ethnology at Osaka and the highenergy physics laboratory (which, among other things, operates Japan's hugely successful electron accelerator and is building the world's most energetic synchrotron radiation source). The hope is that further research institutes will accrete as the university grows.

The fields to which students are assigned are not co-extensive with those of the member-institutes, but are, rather, subsets of them selected for their usefulness for education in research. Thus students assigned to KEK do not join teams making observations in high-energy physics, but are involved with the design of accelerators based on novel techniques or on the application of accelerator technology outside high-energy physics.

The student body is thus scattered for most of the time over more than $200 \mathrm{~km}$ of Japan, but the sense of being detached from the institution is overcome by meetings of the whole group at intervals of six months. One such event had brought them to this beauty spot last week, together with a sizable number of the 200 members of the faculty and various speakers on sci- ence and its social context. Nagakura explained the eclectic nature of the programme by reminding people that Carthage had been a civilization whose prosperity had been much envied at the time, but whose culture had done nothing for Carthage or its successors. Japan, he declared, did not want that reputation.

Can this unique university help to secure that goal? There are some obvious difficulties, not the least of which is that, if students in general are diverted from $\mathrm{PhD}$ courses by the eagerness of companies to employ them, and if the regular universities have first claim on the loyalties of the others, may not the graduate university be disadvantaged in the competition for bright young people?

That seems to be a worry, but not yet a serious one. Nagakura hopes that the attractiveness of the facilities on offer, as well as the reputations of faculty members, will carry the day. One faculty member acknowledges, however, that it may have been necessary to accept lesser qualifications (the equivalent of a two-year master's course) than would the universities of Tokyo or Kyoto. But, he says, members of the faculty also use their personal influence with their academic colleagues at the national universities to recruit able students (whose stipends of $¥ 140,000$ a month — roughly $\$ 1,000-$ are to be increased next year to $¥ 160,000$ ). For what it is worth, casual conversation with those concerned proves that here, as everywhere, they are as bright as paint.

Even so, the first graduations next March will be a sign of the way the wind is blowing. A dozen students will have written and defended dissertations, and will have begun to get jobs for themselves. Most, it is believed, will gravitate towards academic life, but that provokes another question on everybody's mind: if Japan has been short of homegrown PhDs, it also still lacks a sufficient supply of postdoctoral positions in which people can build reputations for themselves (and to which those who have gone overseas for a spell can return while hatching more permanent careers). Will that be Nagakura's next cause? But now, he is too busy planning the new campus at Hayama. Although nothing will be ready for occupation until 1994, the university already knows what it will then be getting. Japan may have been slow to appreciate the importance of graduate students, but it is as deliberate as always. John Maddox 